\title{
Evaluation of the Effectiveness of Reproductive Health Education Program Given to Adolescents
}

\author{
(1) Fatma Başar¹, (1) Betül Yavuz², (1) Havva Yeşildere Sağlam³ \\ ${ }^{1}$ Kütahya Health Sciences University Faculty of Health Sciences, Department of Obstetrics and Gynecology Nursing, Kütahya, Turkey \\ 2Kütahya Health Sciences University Faculty of Health Sciences, Department of Pediatric Nursing, Kütahya, Turkey \\ ${ }^{3}$ Eskişehir Osmangazi University Faculty of Health Sciences, Department of Obstetrics and Gynecology Nursing, Eskişehir, Turkey
}

\begin{abstract}
Aim: This study aimed to determine the effectiveness of reproductive health education for adolescents.

Materials and Methods: We used a quasi-experimental design with pre-test and post-test control groups. A total of 161 adolescents were included in this study, 84 in the intervention group and 77 in the control group. A personal information form and a reproductive health information form were used for data collection. Reproductive health training was given in classes of 2 hours a week (total 14 hours) by the researchers. Before the intervention and 2 months after the intervention, the knowledge level of the students was evaluated using data collection forms.

Results: There was no statistically significant difference ( $p>0.05$ ) between the mean pre-test knowledge scores of the intervention and control groups (17.97 \pm 5.22 and $18.18 \pm 5.28$, respectively). A statistically significant difference was found between the intervention and control groups' mean post-test scores ( $27.51 \pm 3.83$ and $18.36 \pm 5.88$, respectively) $(p<0.05)$.

Conclusion: Students who participated in the reproductive health education program had a higher mean knowledge score for reproductive health after the program, which shows that this reproductive health education program is effective.

Keywords: Adolescent, reproductive health, health education, adolescent health
\end{abstract}

\section{Introduction}

Adolescence is a period defined as the transition from childhood to adulthood, where various physiological and anatomical changes take place $(1,2)$. According to the World Health Organization (WHO), people in the age group of 10-19, which corresponds to approximately 1.2 billion people worldwide, are defined as adolescents (3). Adolescents (aged 10-19 years) represent approximately $16 \%$ of the Turkish population (4). Although it is considered a healthy time of life during which new options and ideas are explored, it is also a vulnerable period of life where sexual identity and self-esteem are developed, and risky behaviors may emerge in terms of reproductive and sexual health $(5,6)$.
The age at sexual activity initiation is gradually decreasing around the world, and it is known that sexual activity is widespread during adolescence $(7,8)$. In Turkey, the first sexual experiences occur, although at a low rate, among those aged 13 years or even younger, although mostly between the ages of 14-15 years $(9,10)$. Previous studies reported that $21.9 \%$ of adolescent girls and $38.7 \%$ of adolescent boys in the USA have their first sexual experiences at the age of 14 years or even younger (11) and that $13.33 \%$ of adolescents in southwest Ethiopia have their first experiences under the age of 10 years, 20\% between the ages of 10 and 14 years, and $66.67 \%$ between the ages of 15 and 19 years (12). 
Teaching a child to be sexually responsible is an important part of sex education (13). However, in Turkeyand worldwide-there are concerns that education about reproductive health and sex may increase the curiosity of adolescents about sexuality and encourage them to become sexually active at an earlier age (14). Previous studies have shown that adolescents whose parents perceive information about reproductive and sexual health as a taboo or shameful topic obtain their information from unofficial sources and thus are left with negative or insufficient knowledge compared to their peers (13-21).

Most countries have policies or strategies that support comprehensive reproductive health and sexual education; however, very few of these countries have implemented and maintained these programs (22). The European Commission and the Ministry of Health (MH) of the Republic of Turkey conducted a "Reproductive Health Program" between 2003 and 2007 with five intervention fields, one of which was the reproductive health of adolescents (23), but this and similar programs were not continued. To meet the informational needs of adolescents concerning reproductive health and sex education, the health and education sectors must work together (24). Based on the results of studies conducted by the WHO on comprehensive reproductive health and sexual education programs included in the curricula in schools, it has been reported that reproductive health and sex education programs actually lead to a delayed initiation of sexual intercourse and decreases in the frequency of intercourse, the number of sex partners and risk taking, and also leads to an increase in the use of condoms and other contraception methods (22). In this context, middle-school children should be provided with a comprehensive reproductive and sexual health education program, including information on the anatomy of the reproductive organs, pregnancy avoidance, and protection against sexually transmitted diseases (2). The literature states that most adolescents prefer classes on reproductive and sexual health education in school $(16,25-27)$ and that they wished that they had counsellors on reproductive and sexual health at schools or in health institutions $(26,28)$.

In the study by Minguez et al. (29), it was observed that students who had access to comprehensive reproductive health services in school health centers engaged in reproductive health education and counselling and more frequently used hormonal contraception. Another study in Nigeria reported that the sex education of adolescents was effective in that the intervention group showed fewer risky sexual behaviors than the control group (2).
There have been studies conducted in Turkey with university students on reproductive health and sexual health education (19,30-32), and studies in the literature have been conducted with adolescents about sexual health education $(17,33,34)$ and reproductive health $(6,35-44)$. However, the number of studies examining the effectiveness of sexual health $(33,34)$ and reproductive health education (41) provided for adolescents between the ages of 11 and 14 years is limited.

School nurses play an important role as members of the school health team by providing education on reproductive health and sexual health at schools around the world (45). Although not all schools in Turkey have a school nurse yet, the MH has issued the Regulation on the Amendment of Nursing Regulation regarding the duties, powers, and responsibilities of school nurses in terms of school health. It states that the education provided by the school nurse includes reproductive health and sexual health education (46). The present study, one of the few investigating the efficacy of reproductive health education for Turkish adolescents, is the first to investigate the effectiveness of reproductive health education for adolescents in Kütahya, which is located in the inner Aegean region of Turkey. It is proposed that this study will form the basis for future studies on improving reproductive health in adolescents.

This study was conducted to determine the efficacy of the reproductive health education program given to adolescents.

The hypotheses of the study were:

Hypothesis 1: The intervention group's mean post-test knowledge score will be higher than their mean pre-test knowledge score.

Hypothesis 2: The intervention group's mean post-test knowledge score will be higher than the control group's mean post-test knowledge.

\section{Materials and Methods}

\section{Study Design and Participants}

This study used a quasi-experimental design with pre-test and post-test control groups. The research was conducted in a single center. The study population consisted of 196 students aged 11 to 14 years who attended secondary school in Kütahya between March 2017 and July 2017.

This school is one of the schools that represents the general socio-demographic characteristics of Kütahya, and it has the largest student population. Power analysis was done with the C*Power program. The sample size was 
calculated by using the effect size in the sample size calculation. The total sample size was determined to be 128 in calculations based on a type I error rate of $5 \%$, a medium effect size of 0.25 and a power ratio of $80 \%$. Considering data losses, 130 students were planned to be included in the sample. However, 84 students were included in the intervention group and 77 students in the control group in the study. No blinding process was used in the data collection process of the study. There were a total of 6 mixed classes in the school. The classes were selected by a simple random sampling method (coin toss) and assigned to either the control or intervention group. In this way, the control group was comprised of 3 classes and the intervention group was comprised of 3 classes. The students in these classrooms who volunteered to participate in the study formed the sample of the study. In this way, students were prevented from getting information about education from each other. The data were collected in the classroom environment at the school, and training sessions were held at hours deemed appropriate by the school. The training hours and the training area are determined by the school directorate.

The inclusion criteria were being between 11 and 14 years old, having reading and writing literacy, and parental and student verbal and written consent. Students' participation was voluntary.

\section{Data Collection}

\section{Measurements}

The study data were collected using a personal information form and a reproductive health information form. Expert opinion was sought in the preparation of the reproductive health information form. In addition, the adolescents in the intervention group were provided with training using a booklet entitled "Reproductive Health" prepared by the researchers based on the literature and expert opinions. After obtaining expert opinion, the final form of the data collection form and training booklet was given.

The data collection tools were examined by the Kütahya Provincial Directorate of National Education Guidance Research Center for their suitability for the students of that age group and in terms of clarity. After this examination, they were deemed to be appropriate.

Personal information form: the personal information form consisted of questions about the socio-demographic characteristics (age, gender, family type, economic situation, etc.) and the reproductive health knowledge of the adolescents and the socio-demographic characteristics of the parents (educational status, marital status, etc.).

Reproductive health information form: this form was designed by the researchers following a literature review and was evaluated by an expert $(7,19,32,47,48)$. The reproductive health information form consisted of 33 questions measuring the level of knowledge regarding changes in the adolescent period, reproductive health and reproductive rights of adolescents, sexually transmitted diseases, anatomy and physiology of the male and female reproductive systems, and risky acts of behavior. One point was awarded for each correct answer and 0 points were awarded for each incorrect answer on the reproductive health information form. The lowest possible score was 0 , and the highest possible score was 33 .

Higher scores on the reproductive health information form indicated that the reproductive health knowledge levels of the adolescents were increasing.

\section{Intervention}

The intervention group: the adolescents included in the intervention group were first asked to complete the personal information form and the reproductive health information form as a preliminary test. Next, they participated in a reproductive health education program for a total of 14 hours ( 2 hours per week for 7 weeks). In this program, girls and boys were educated by the researcher in separate groups.

In the training given to the adolescents within the scope of the reproductive health education program, reproductive health education booklets and a PowerPoint presentation based on the booklets were used $(40,19,47)$. Additionally, models were shown while explaining the anatomy of the reproductive organs.

Six weeks after the training was provided by the researcher within the scope of the reproductive health training program, the adolescents in the intervention group were asked to complete the reproductive health information form for a second time in a classroom environment at the school (Table I).

The control group: two forms, the personal information form and the reproductive health information form (in the form of a pre-test), were completed by those adolescents in the control group. No intervention was made for the control group other than the normal procedures during this process.

The reproductive health information form was administered six weeks later as a post-test. Educating the 


\begin{tabular}{|l|l|l|}
\hline \multicolumn{2}{|l|}{ Table I. Reproductive health education program for adolescents in Kütahya, Turkey } & \multicolumn{2}{|l|}{ Education time } \\
\hline Week & Education module & \\
\hline $1^{\text {st }}$ & Introduction, meeting the students & \\
\cline { 1 - 2 } $2^{\text {nd }}$ & Adolescent period, changes in the adolescent period & \multirow{2}{*}{ hours } \\
\hline $3^{\text {rd }}$ & Reproductive system anatomy and physiology & \\
\hline $4^{\text {th }}$ & Risky behavior in the adolescent period & \\
\hline $5^{\text {th }}$ & Sexually transmitted diseases and prevention & \\
\hline $6^{\text {th }}$ & Reproductive health, reproductive rights & \\
\hline $7^{\text {th }}$ & Closing, general evaluation & \\
\hline
\end{tabular}

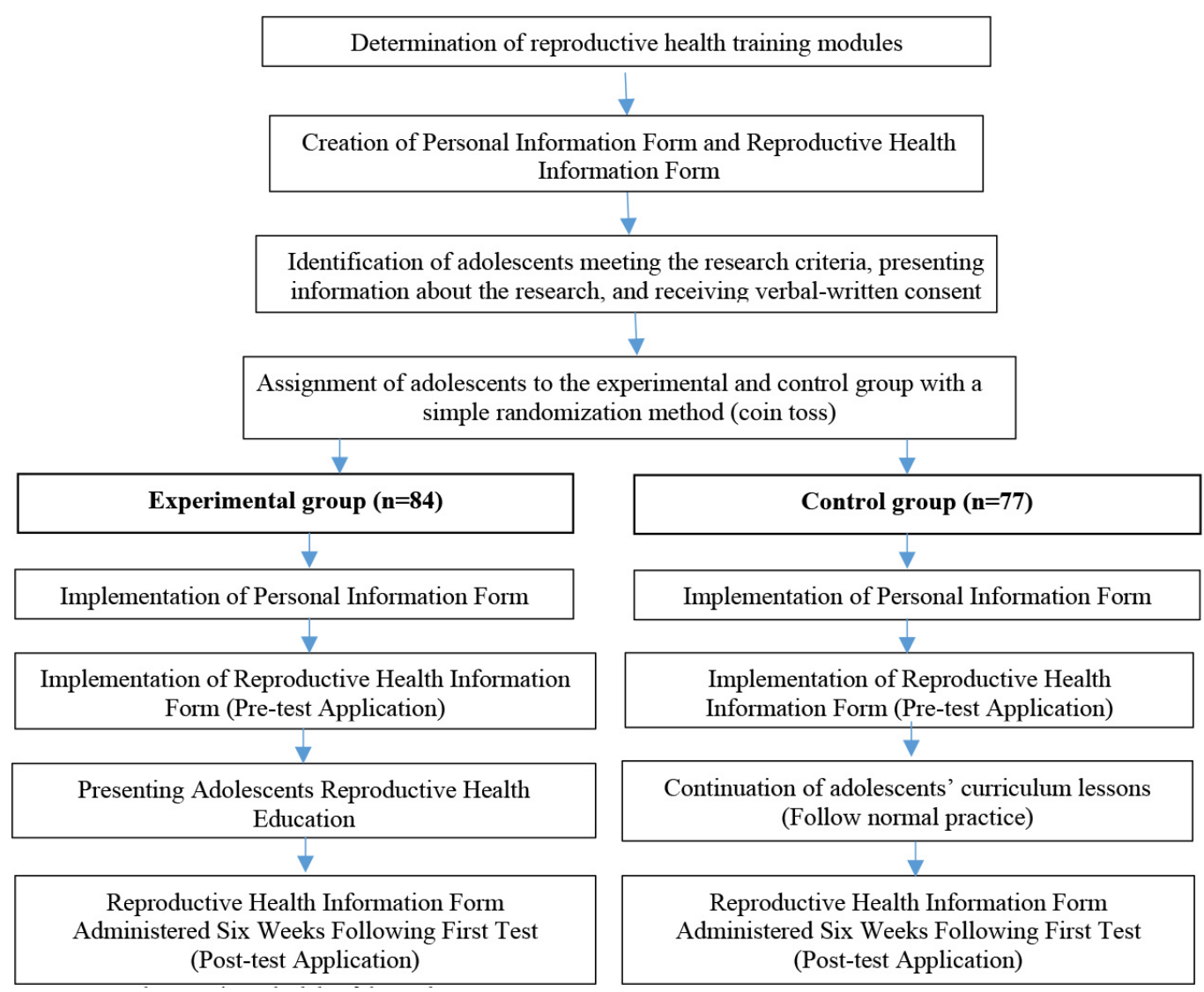

Figure 1. Implementation schedule of the study

intervention group but not providing education for the control group creates an ethical problem. Therefore, the control group received reproductive health education after they completed the post-test (Figure 1).

The purpose of the study was explained to each student and their family, and joint consent was obtained. Ethical approval for the study was obtained from the Ethics Committee of the Non-Interventional Clinical Investigations Eskişehir Osmangazi University (IRB no. 201707). The Directorate of National Education of Kütahya issued a research permit (dated on 05.04.2016, numbered 53490996-44-E.3831220).

\section{Statistical Analysis}

All analyses were performed using the Statistical Package for Social Sciences (SPSS) program, version 20. Shapiro-Wilk test was used to examine the distribution of the data and it was observed that the data were distributed normally. Therefore, parametric tests were used in the analysis of the data. Numbers (n), percentages (\%), chi-square analyses 
$\left(X^{2}\right)$ and t-tests for dependent and independent groups were used during the data analysis (49). Chi-square test was used to examine the difference between intervention and experimental group characteristics. The t-test was used to evaluate the knowledge levels of the students in the intervention and control groups before and after the education. The level of statistical significance was accepted as $\alpha=0.05$.

\section{Results}

The adolescents' mean age was $12.83 \pm 0.47$ years in the control group and $12.80 \pm 0.54$ years in the intervention group. Whereas there was no statistically significant difference between the groups in terms of age, gender, number of siblings, area of longest residence, health insurance, current residence, and family type ( $p>0.05)$, there was a statistically significant difference in the income level of the adolescents' families ( $p<0.05$; Table II).

There was no statistically significant difference between the intervention and control groups in terms of maternal education level, mother's working status, or parental marital status ( $p>0.05)$; however, there was a statistically significant difference between the groups in terms of the father's education level and father's occupation $(p<0.05$; Table III).

There was no statistically significant difference between the intervention and control groups in terms of hearing about the reproductive health concept, reproductive health knowledge level, or receipt of reproductive health education at school in the past ( $p>0.05$; Table IV).

The mean pre-test reproductive health information score of the adolescents in the intervention group was $17.97 \pm 5.22$, and the mean pre-test score of the adolescents in the control group was $18.18 \pm 5.28$. There was no statistically significant difference between the mean pre-test scores of the adolescents in the intervention and control groups ( $p>0.05$; Table V).

The mean post-test reproductive health information score of the adolescents in the intervention group was $27.51 \pm 3.83$, and the mean post-test score of the adolescents in the control group was $18.36 \pm 5.88$. There was a statistically significant difference between the mean post-test scores of the adolescents in the intervention and control groups $(p<0.05 ;$ Table V).

In-group comparisons of the intervention and control groups related to reproductive health information pre-test
Table II. Comparison of socio-demographic characteristics of adolescents in Kütahya, Turkey

\begin{tabular}{|c|c|c|c|c|}
\hline Characteristics & Control & Intervention & & \\
\hline \multirow[t]{3}{*}{ Age } & Mean \pm SD & Mean \pm SD & $\mathbf{t}$ & p-value \\
\hline & $12.83 \pm 0.47$ & $12.80 \pm 0.54$ & 0.268 & 0.789 \\
\hline & n (\%) & n (\%) & $x^{2}$ & p \\
\hline \multicolumn{5}{|l|}{ Gender } \\
\hline Female & $43(49.4)$ & $44(50.6)$ & \multirow{2}{*}{0.194} & \multirow{2}{*}{0.660} \\
\hline Male & $34(45.9)$ & $40(54.1)$ & & \\
\hline
\end{tabular}

Number of siblings

\begin{tabular}{|l|l|l|l|l|}
\hline 1 & $12(48.0)$ & $13(52.0)$ & & \multirow{2}{*}{0.238} \\
\cline { 1 - 3 } 2 & $42(49.4)$ & $43(50.6)$ & 0.888 \\
\cline { 1 - 3 } 3 and more & $23(45.1)$ & $28(54.9)$ & & \\
\cline { 1 - 3 } & & &
\end{tabular}

Area of longest residence

\begin{tabular}{|l|c|c|c|c|}
\hline City & $68(47.2)$ & $76(52.8)$ & \multirow{2}{*}{0.199} & 0.655 \\
\cline { 1 - 3 } Rural area & $9(52.9)$ & $8(47.1)$ & & \\
\hline
\end{tabular}

Health insurance

\begin{tabular}{|l|c|c|l|l|}
\hline Yes & $73(47.1)$ & $82(52.9)$ & \multirow{2}{*}{0.887} & 0.427 \\
\cline { 1 - 3 } No & $4(66.7)$ & $2(33.3)$ & & \\
\hline
\end{tabular}

Current residence

\begin{tabular}{|l|c|c|c|c|}
\hline Home/Family & $74(49.0)$ & $77(51.0)$ & \multirow{2}{*}{1,358} & 0.244 \\
\cline { 1 - 3 } $\begin{array}{l}\text { Dormitory/ } \\
\text { Housing }\end{array}$ & $3(30.0)$ & $7(70.0)$ & & \\
\hline
\end{tabular}

Family type

\begin{tabular}{|l|c|c|c|c|}
\hline \begin{tabular}{l|l|l|} 
Immediate \\
family
\end{tabular} & $64(47.4)$ & $71(52.6)$ & & \\
\cline { 1 - 3 } Extended family & $11(55.0)$ & $9(45.0)$ & 0.927 & 0.629 \\
\cline { 1 - 3 } Broken family & $2(33.3)$ & $4(66.7)$ & & \\
\hline
\end{tabular}

Income status

\begin{tabular}{|l|c|c|c|c|}
\hline $\begin{array}{l}\text { Income exceeds } \\
\text { expenses }\end{array}$ & $19(32.8)$ & $39(67.2)$ & & \\
\cline { 1 - 3 } $\begin{array}{l}\text { Income equal to } \\
\text { expenses }\end{array}$ & $55(60.4)$ & $36(39.6)$ & 13,585 & $\mathbf{0 . 0 0 1}$ \\
\cline { 1 - 3 } $\begin{array}{l}\text { Income is less } \\
\text { than expenses }\end{array}$ & $3(25.0)$ & $9(75.0)$ & & \\
\hline \multicolumn{2}{|l}{ SD: Standard deviation } \\
\hline
\end{tabular}


and post-test score averages were examined. The mean pre-test and post-test scores of the intervention group were $17.97 \pm 5.22$ and $27.51 \pm 3.83$, respectively. The difference between the mean pre-test and post-test scores of the intervention group was found to be statistically significant $(p<0.05 ;$ Table $V)$. The mean pre-test and post-test scores

Table III. Comparison of the characteristics of the adolescents' families in Kütahya, Turkey

\begin{tabular}{|l|c|c|c|c|}
\hline Characteristics & Control & Intervention & & \\
\hline & $\mathbf{n}(\%)$ & $\mathbf{n}(\%)$ & $\mathbf{X}^{2}$ & p-value \\
\hline
\end{tabular}

Mother's education level

\begin{tabular}{|l|c|c|c|c|}
\hline Primary school & $40(43.5)$ & $52(56.5)$ & & \\
\cline { 1 - 3 } High school & $29(50.9)$ & $28(49.1)$ & \multirow{2}{*}{2,617} & 0.270 \\
\cline { 1 - 3 } $\begin{array}{l}\text { University and } \\
\text { above }\end{array}$ & $8(66.7)$ & $4(33.3)$ & & \\
\cline { 1 - 3 } & & &
\end{tabular}

Father's education level

\begin{tabular}{|l|c|c|c|c|}
\hline Primary school & $12(38.7)$ & $19(61.3)$ & & \\
\cline { 1 - 3 } High school & $47(57.3)$ & $35(42.7)$ & \multirow{2}{*}{6,044} & $\mathbf{0 . 0 4 9}$ \\
\cline { 1 - 3 } $\begin{array}{l}\text { University and } \\
\text { above }\end{array}$ & $18(37.5)$ & $30(62.5)$ & & \\
\hline
\end{tabular}

\section{Mother's employment status}

\begin{tabular}{|l|l|l|l|l|}
\hline Employed & $22(48.9)$ & $23(51.1)$ & \multirow{2}{*}{0.028} & \multirow{2}{*}{0.866} \\
\cline { 1 - 3 } Unemployed & $55(47.4)$ & $61(52.6)$ & & \\
\hline
\end{tabular}

\section{Father's occupation}

\begin{tabular}{|l|c|c|c|c|}
\hline Laborer & $40(62.5)$ & $24(37.5)$ & & \\
\cline { 1 - 3 } Civil Servant & $18(34.6)$ & $34(65.4)$ & \multirow{2}{*}{10,038} & \multirow{2}{*}{$\mathbf{0 . 0 1 8}$} \\
\cline { 1 - 3 } Self-employed & $14(40.0)$ & $21(60.0)$ & & \\
\cline { 1 - 3 } Retired & $5(50.0)$ & $5(50.0)$ & & \\
\hline
\end{tabular}

\section{Marital status}

\begin{tabular}{|l|c|c|c|c|}
\hline Married & $68(45.9)$ & $80(54.1)$ & \multirow{2}{*}{2,597} & \multirow{2}{*}{0.148} \\
\cline { 1 - 3 } Divorced & $9(69.2)$ & $4(30.8)$ & & \\
\hline
\end{tabular}

of the control group were $18.18 \pm 5.28$ and $18.36 \pm 5.88$, respectively. There was no statistically significant difference between the mean pre-test and post-test scores of the control group ( $p>0.05$; Table $V$ ).

\section{Discussion}

It is thought that including reproductive health education in school curricula in developing countries will increase adolescents' reproductive health knowledge and decrease reproductive health problems. In this study, the efficacy of the "Reproductive Health Education Program" in increasing reproductive health knowledge among adolescents was evaluated.

It was determined that the adolescents in the intervention and control groups were similar in terms of age, gender, number of siblings, place of residence, health insurance status, and family type ( $p>0.05)$ but different regarding economic status $(p<0.05$; Table II). It is important for the reliability of the study that the characteristics of the students in the experimental and control groups are similar.

Table IV. Adolescents' views on reproductive health and reproductive health education in Kütahya, Turkey

\begin{tabular}{|l|l|c|l|l|}
\hline Characteristic & Control & Intervention & & \\
\hline & $\mathrm{n}(\%)$ & $\mathrm{n}(\%)$ & $\mathrm{X}^{2}$ & $\mathrm{p}$-value \\
\hline
\end{tabular}

Heard the concept of reproductive health

\begin{tabular}{|l|c|c|l|l|}
\hline Yes & $41(47.1)$ & $46(52.9)$ & \multirow{2}{*}{0.037} & \multirow{2}{*}{0.875} \\
\cline { 1 - 3 } No & $36(48.6)$ & $38(51.4)$ & & \\
\hline
\end{tabular}

Knowledge status on reproductive health

\begin{tabular}{l|l|l|l|l}
\cline { 1 - 3 } Sufficient & $26(43.3)$ & $34(56.7)$ & \multirow{2}{*}{0.774} & 0.379 \\
\cline { 1 - 3 } Insufficient & $51(50.5)$ & $50(49.5)$ & & \\
\cline { 1 - 3 }
\end{tabular}

Obtained reproductive health education at school in the past

\begin{tabular}{|l|l|l|l|l|}
\hline Yes & $17(44.7)$ & $21(55.3)$ & \multirow{2}{*}{0.190} & 0.663 \\
\cline { 1 - 3 } No & $60(48.8)$ & $63(51.2)$ & & \\
\hline
\end{tabular}

Table V. Comparison of reproductive health pre-test and post-test score averages

\begin{tabular}{|l|c|c|c|c|}
\hline Table V. Comparison of reproductive health pre-test and post-test score averages & t & Intervention & p-value \\
\hline Characteristics & Control & Mean \pm SD & 0.248 & 0.804 \\
\hline Pre-test score average & $18.18 \pm 5.28$ & $17.97 \pm 5.22$ & $-11,579$ & $<0.001$ \\
\hline \multirow{3}{*}{ Post-test score average } & $18.36 \pm 5.88$ & $27.51 \pm 3.83$ & & \\
\cline { 2 - 5 } & $\mathrm{t}=-0.338$ & $\mathrm{t}=-18,537$ & $\mathbf{p}<0.001$ & \\
\hline
\end{tabular}


In the current study, it was determined that the adolescents in the intervention and control groups were similar in terms of the mother's education level, working status, and marital status ( $p>0.05)$. However, they differed regarding the father's education level and occupation ( $p<0.05$; Table III). Golbasi and Taskin (42) also reported in their study that the adolescents in the intervention and control groups were similar in terms of the mother's educational level, working status, and family type but differed regarding the father's educational level. In this study, it was observed that the group characteristics were different from each other in terms of the father's education level and occupation. Students studying in the province where the study was conducted can live in villages and towns near the city. It is thought that the different cultural and family structure of the students coming from the villages and towns near the city, the access to education and the different workforce preferences may be the cause of this difference.

In the current study, it was observed that adolescents were similar in terms of hearing about the concept of reproductive health, having knowledge about reproductive health, and having received reproductive health education at school in the past ( $p>0.05$; Table IV). Handayani et al. (35) determined in their study that adolescents in the intervention and control groups were not similar in terms of having knowledge about reproductive health.

For reproductive health, the mean pre-test scores of the adolescents in the intervention and control groups were similar ( $p>0.05)$, and it was observed that the mean posttest score of the intervention group was higher than that of the control group ( $p<0.05$; Table $V)$. These results showed that the knowledge level of adolescents who received reproductive health education was higher than that of adolescents who did not receive education on this issue (control group). Previous studies also reported that the reproductive health level of knowledge of the intervention group who received reproductive health education was higher than that of the control group $(7,37,37,42)$.

Previous studies examining the mean pre- and posteducation reproductive and sexual health knowledge levels of adolescents reported that these knowledge levels were higher post education $(36,41,43)$. In addition, it has been stated that the implemented reproductive health education program improved knowledge and behavior about sexuality and decision making for both girls and boys (41). Other previous studies on this subject reported that their reproductive health knowledge level of adolescent through post education was higher than that before education $(39,44)$.

Parwej et al. (6) reported that after training was given for reproductive health, adolescents in a conventional education group and a peer education group had significantly higher reproductive health knowledge scores than adolescents in the control group. It was also determined that the posteducation reproductive health knowledge scores in the conventional education group were similar to those in the peer education group.

A study that investigated the effects of peer education on adolescents' reproductive health knowledge reported that the knowledge level regarding reproductive health of adolescents in the intervention group was higher than that of adolescents in the control group (40). In another study that investigated the effects of a sex education program on adolescents, a statistically significant increase in adolescents' knowledge levels regarding changes during adolescence was found (17).

The intragroup comparisons of both groups (intervention versus control) showed that the mean posttest reproductive health knowledge score was higher than the mean pre-test score of the intervention group $(p<0.05)$ and that the mean pre-test and post-test scores of the control group were similar ( $p>0.05$; Table $V)$. The results of the current study were similar to those of previous studies $(7,31,37)$. Taylor et al. (50) stated in their study that reproductive health education applied to adolescents can be effective in preventing sexually transmitted diseases and unwanted pregnancies and increases their knowledge about reproductive health. de Castro et al. (51) reported that sexual health education for adolescents is effective in developing knowledge and attitudes about sexual and reproductive health and creating a positive effect on individuals' behaviors. When the relevant literature is examined, it is seen that reproductive health training for adolescents and young people is extremely effective. Young people are a high-risk group in terms of reproductive and sexual health, and it is extremely important that they can benefit from holistic, comprehensive reproductive health education. There are no standardized reproductive health training programs for adolescents in our country. Due to the family and cultural structure of our country, adolescents may face various obstacles such as inability to access services, embarrassment, stigma, lack of tolerance, negative attitudes and behaviors when faced with a problem related to reproductive and sexual health or when they are asked to obtain information. Due to various obstacles, adolescents 
access information about reproductive health through informal means (media, internet, friends, etc.). The rapid socio-cultural change experienced makes adolescents who have not received adequate training in reproductive health during adolescence open to risks in sexual and reproductive health issues. For this reason, it is necessary to organize comprehensive training programs in order to prevent risky sexual behaviors, unwanted pregnancies, and/or sexually transmitted infections, which can be seen due to the lack of knowledge of adolescents, and ultimately to ensure that adolescents are safe in terms of reproductive health. The literature consistently shows the benefits of reproductive health education. This is in alignment with the present study, which illustrated that reproductive health education programs provided to adolescents are effective. Education programs that increase adolescents' reproductive health knowledge level in detail during secondary education may be effective in improving their reproductive health.

\section{Study Limitations}

From a country where data are limited (Turkey), the effectiveness of the implemented reproductive health education for adolescents is expected to provide an important contribution to the literature. Although the contribution of the study is important, there are limitations. In this study, randomization could not be done by sample selection. The study was conducted at a single center in Turkey. Since the city where the study was conducted does not represent the whole country, generalizations cannot be made. Due to the short duration of the educational program (limited to seven weeks), the long-term impact of the program and its sustainability could not be assessed. For this reason, long-term evaluation studies are necessary. In addition, due to the traditional structure of Turkish society, it is thought that students will be able to reach the right information about reproductive health by means of education program process and answering the questionnaire questions.

\section{Conclusion}

This reproductive health education program effectively created positive changes and attitudes in terms of the knowledge of reproductive health among secondary school students. As the study findings reveal, there was a significant increase in the adolescents' knowledge level after the training. Interventions that increase knowledge of reproductive health provide protection and improve adolescents' reproductive health. A widespread adoption of reproductive health education programs in schools is crucial to prevent risky behaviors. It is recommended that secondary school education curricula include reproductive and sexual health education.

\section{Ethics}

Ethics Committee Approval: Ethical approval for the study was acquired from the Ethics Committee of the NonInterventional Clinical Investigations Eskişehir Osmangazi University (IRB no. 2017-07).

Informed Consent: Informed consent was obtained.

Peer-review: Externally peer-reviewed.

\section{Authorship Contributions}

Design: F.B., H.Y.S., Data Collection or Processing: F.B., H.Y.S., Analysis or Interpretation: F.B., B.Y., H.Y.S., Writing: F.B., B.Y., H.Y.S.

Conflict of Interest: No conflict of interest was declared by the authors.

Financial Disclosure: The authors declared that this study received no financial support.

\section{References}

1. Agampodi SB, Agampodi TC, Ukd P. Adolescents perception of reproductive health care services in Sri Lanka. BMC Health Serv Res 2008; 8:98.

2. Esere MO Effect of sex education programme on at-risk sexual behaviour of school-going adolescents in Ilorin, Nigeria. Afr Health Sci 2008; 8:120-5.

3. WHO. WHO recommendations on adolescent sexual and reproductive health and rights, WHO. 2018a. Available from: https://apps.who.int/iris/bitstream/hand le/10665/275374/9789241514606-eng.pdf?ua=1

4. Hacettepe University Institute of Population Studies; Turkey Demographic and Health Survey. 2018. Available from: http:// www.hips.hacettepe.edu.tr/tnsa2018/rapor/TNSA2018_ana_ Rapor.pdf.

5. Denno DM, Hoopes AJ, Chandra-Mouli V. Effective strategies to provide adolescent sexual and reproductive health services and to increase demand and community support. J Adolesc Health 2015; 56:522-41.

6. Parwej S, Kumar R, Walia I, Aggarwal AK. Reproductive health education intervention trial. Indian / Pediatr 2005; 72:287-91.

7. Sommart I, Sota C. The effectiveness of a school-based sexual health education program for junior high school students in Khon Kaen, Thailand. Procedia Soc Behav Sci 2013; 91:208-14.

8. Kaplan DL, Jones E), Olson EC, Yunzal-Butler CB. Early age of first sex and health risk in an urban adolescent population. I Sch Health 2013; 83:350-6.

9. Kara B, Hatun Ş, Aydoğan M, Babaoğlu K, Gökalp AS. Evaluation of the health risk behaviors of high school students in Kocaeli. Çocuk Sağlığı ve Hastalıkları Derg 2003; 46:30-7.

10. Ögel K, Eke Ceyda Y, Erdoğan N, Taner S, Erol B. Sexuality research report among youth in Istanbul. İstanbul, Yeniden Yayın, 2005. 
11. Abma JC, Martinez GM. Sexual Activity and Contraceptive Use Among Teenagers in the United States, 2011-2015. National health statistics reports; no 104. Hyattsville, MD: National Center for Health Statistics. 2017. Available from: https://www. cdc.gov/nchs/data/nhsr/nhsr104.pdf

12. Ena L, Hurissa BF, Aliyu SA. Knowledge, Attitudes and Practices towards Risky Sexual Behaviors among Adolescents of Jimma University Community High School, South West Ethiopia, 2015. Womens Health (Lond) 2016; 5:1-7.

13. M) Hockenberry, D. Wilson. Wong's nursing care of infants and children. In:Rodgers CC (eds). Health Promotion of the SchoolAge Child and Family. 10th ed. Canada, Elsevier Mosby, 2015, p. 580-1.

14. Gürsoy E, Gençalp NS. The importance of sexual health education. Aile ve Toplum Dergisi 2010; 11:29-36.

15. Aydoğan i. Female students' problems who study in general high schools. Aile ve Toplum Dergisi 2011; 7:47-68.

16. Kennedy EC, Bulu S, Harris J, Humphreys D, Malverus, J, Gray NJ. These issues aren't talked about at home": a qualitative study of the sexual and reproductive health information preferences of adolescents in Vanuatu. BMC Public Health 2014; 14:770.

17. Ozturk B, Siyez DM. An investigation of the effectiveness of sexual education program for 6th grade students. Ege Journal of Education 2015; 16:30-55

18. Roudsari RL, Javadnoori $M$, Hasanpour $M$, Hazavehei $\mathrm{MH}$ Taghipour A. Socio-cultural challenges to sexual health education for female adolescents in Iran. Iran I Reprod Med 2013; 11:101-10.

19. Dag $\mathrm{H}$, Donmez $\mathrm{S}$, Sirin $\mathrm{A}$, Kavlak $\mathrm{O}$. University youth reproductive and sexual health knowledge and peer education. I Anatol Nurs and Health Sci 2012; 15:10-7.

20. Bulut F, Gölbaşı Z. The evaluation of communication between adolescent girls and their mothers related to sexual Issues. TAF Prev Med Bull 2009; 8:27-36.

21. Korkmaz Cetin S, Bildik T, Erermis S, et al. Sexual behavior and sources of information about sex among male adolescents: an 8-year followup. Turk J Psychiatry 2008; 19:390-7.

22. WHO. World Health Organization recommendations on adolescent sexual and reproductive health and rights. Comprehensive sexuality education provision. WHO. 2018b. Available from: https://apps.who.int/iris/bitstream/hand le/10665/275374/9789241514606-eng.pdf?ua=1

23. T.C. Sağlık Bakanlığı (2004). Türkiye Üreme Sağlığı Programı Hizmet Çerçevesi Raporu. pp. 7-8. Available from: https://sbu. saglik.gov.tr/Ekutuphane/Yayin/427

24. T.C. Sağlık Bakanlığı Ana Çocuk Sağlığı ve Aile Planlaması Genel Müdürlüğü (2009). Gençlere Yönelik Üreme Sağlığı Hizmetleri Katılımcı Kitabı. Available from: https://sbu.saglik.gov.tr/ Ekutuphane/Yayin/328

25. Shariati M, Babazdeh R, Mousavi SA, Najmabadi KM. Iranian adolescent girls' barriers in accessing sexual and reproductive health information and services: a qualitative study. I Fam Plann Reprod Health Care 2014; 40:270-5.

26. Biri A, Korucuoğlu Ü, Yılmaz E, Şimşek Ç, Aksakal FN, ilhan M. Evaluation of adolescent girl's requirement of knowledge on sexuality. Turk J Obstet Gynecol 2007; 4:104-7.

27. Kotecha PV, Patel S, Baxi RK, Mazumdar VS, Misra S, Modi E. Reproductive health awareness among rural school going adolescents of Vadodara district. Indian I Sex Transm Dis AIDS 2009; 30:94-9.

28. Aydın M. Undergraduate students' knowledge and opinions about sexual health training and sexual health. JETPR 2019; 5:1-13.

29. Minguez M, Santelli JS, Gibson E, Orr M, Samant S. Reproductive health impact of a school health center. J Adolesc Health 2015. $56: 338-44$

30. Duman BN, Yılmazel G, Topuz \$, BaşCl AB, Koçak YD, Büyükgönenç $L$. The knowledge, attitudes and behaviours of the university youths about reproduction health and sexual health. Yıldırım Beyazıt Üniversitesi Sağlık Bilimleri Fakültesi Hemşirelik E-Dergisi. 2015; 3:19-32.

31. Pınar G, Taskın L. The efficiency of sexual health and reproductive health training program developed for university youth. Gulhane Med I 2011; 53:1-8.

32. Karabulutlu O, Kılıç M. The determination of knowledge levels of university students about sexual health and reproductive health. Journal of Anatolia Nursing and Health Sciences 2011; 14:39-45.

33. Esen E, Siyez DM. Effect of sexual health education programme on 9th grade students' sexual health knowledge and attitude. H.U. Journal of Education 2017; 32:560-80.

34. Güler S, Yöndem ZD. The effect of group guidance activities regarding adolescence and sexual health education on knowledge and attitudes of 6th graders. Element Educ Online 2007; 6:2-10.

35. Handayani F, Bestari AD, Nurhayati. The effects of learning by reproductive health module on knowledge, attitudes and practices regarding adolescent reproductive health in bandung district. J Physics 2019; Conf. Series 1179.

36. Phulambrikar RM, Lahanubhau Kharde A, Mahavarakar VN, Phalke DB, Phalke VD. Effectiveness of interventional reproductive and sexual health education among school going adolescent girls in rural area. Indian I Community Med 2019; 44:378-82.

37. Ataman $\mathrm{H}$, Kömürcü $\mathrm{N}$. Effectiveness of the sexual health/ reproductive health education Given to Turkey adolescents who use alcohol or substance. I Addict Nurs 2017; 28:71-8.

38. Topatan S, Demirci N. The efficiency of reproduction health education given to adolescents during the postpartum Period. Pediatr Adolesc Gynecol 2015; 28:297-303.

39. Nair M, Paul MK, Leena $M$, et al. Effectiveness of a reproductive sexual health education package among school going adolescents. Indian / Pediatr 2012; 79:64-8.

40. Okanlawon FA, Asuzu MC. Effect of peer education intervention on secondary school adolescents' reproductive health knowledge in Saki, Nigeria. Afr J Med Med Sci 2011; 40:353-60.

41. Madeni F, Horiuchi S, lida M. Evaluation of a reproductive health awareness program for adolescence in urban Tanzania-A quasiexperimental pre-test post-test research. Reprod Health 2011; 8:21.

42. Golbasi Z, Taskin L. Evaluation of school-based reproductive health education program for adolescent girls. Int I Adolesc Med Health 2009; 21:395-404.

43. Ersin F, Bahar Z. Effects of training for reproductive health on knowledge of reproductive health and behavior in adolescents. Int J Caring Sci 2009; 2:73-81. 
44. Rao RSP, Lena A, Nair N, Kamath V, Kamath A. Effectiveness of reproductive health education among rural adolescent girls: a school based intervention study in Udupi Taluk, Karnataka. Indian J Med Sci 2008; 62:439-43.

45. Bektaş M, Aydın B. Role and functions of school nurse. J Pediatr Nurs Special Topics 2018; 4:52-64.

46. T.C. Sağlık Bakanlığı. (2011). Hemşirelik Yönetmeliğinde Değişiklik Yapılmasına Dair Yönetmelik. Ankara: T.C. Sağlık Bakanlığı. Erişim tarihi: 20.03.2020. Erişim adresi: https://www. resmigazete.gov.tr/eskiler/2011/04/20110419-5.htm

47. Reis M, Ramiro L, De Matos MG, Diniz JA. The effects of sex education in promoting sexual and reproductive health in Portuguese university students. Procedia Soc Behav Sci 2011; 29:477-85.
48. Gölbaşı Z. Reproductive health problems and affecting factors in adolescent period. / Anatol Nurs and Health Sci 2005; 8:1008.

49. Büyüköztürk \$. Data analysis handbook for social sciences statistics, research design SPSS applications comments. 8th ed. Ankara, Pegem A Yayıncılık, 2014.

50. Taylor RJ, Shade K, Lowry SJ, Ahrens K. Evaluation of reproductive health education in transition-age youth. Child Youth Serv Rev 2020; 108:104530.

51. de Castro F, Rojas-Martínez R, Villalobos-Hernández A, et al. Sexual and reproductive health outcomes are positively associated with comprehensive sexual education exposure in Mexican high-school students. PLoS One 2018; 13:e0193780. 